\title{
Gramsci y la sociología marxista
}

z del lenguaje: algunas notas para la reflexión.

Gramsci and the Marxist Sociology

of Language: some notes toward Reflection.

En la teoría social, el marcado énfasis que los teóricos marxistas han brindado a los procesos económicos y políticos ha alterado la naturaleza "holística" del materialismo histórico dando lugar a identificarlo como una corriente de pensamiento reduccionista y determinista. Como ya ha sido demostrado por muchos estudiosos, Antonio Gramsci fue uno de los primeros marxistas occidentales que se planteó examinar las estructuras fundamentales del marxismo, proporcionando una sistemática re-construcción de la problemática marxista y ampliando el horizonte de su aplicación. El teórico y revolucionario italiano se había establecido como propósito de vida restaurar la flexibilidad original de Marx. En ese sentido, Gramsci ha logrado desarrollar una teoría del conocimiento historiográfica y teórico-política, y una metodología para el estudio de la historia y la sociedad sobre la base de los conceptos de humanismo, historicismo y hegemonía inspirados en los escritos de Marx. En este intento, Gramsci revalúa el carácter superestructural del marxismo y la ciencia y le dedica una atención particular al análisis del fenómeno cultural en la teoría y práctica marxista. La razón es sencilla. El socialismo significa, desde su perspectiva, fundamentalmente una reorganización de la cultura y la adquisición de una conciencia superior (Gramsci 1975, p. 21).

Una significativa cantidad de los textos de Gramsci tratan de los problemas vinculados al arte, teatro, 
literatura, crítica literaria, poesía y lenguaje. Ciertamente, Gramsci no analiza sistemáticamente todos estos fenómenos, como tampoco elabora una teoría marxista de la estética, del arte o del lenguaje. Sin embargo, como Angliani (1967) y Petronio (1958) lo hicieron notar hace varios años, Gramsci estructura un marco fundamental del análisis marxista en torno a la crítica literaria, al arte y al lenguaje. Gramsci analiza estos fenómenos desde la perspectiva general de la filosofía de la praxis tomando en cuenta el objetivo práctico de la conquista de la hegemonía por el proletariado. Su análisis de los fenómenos culturales es, entonces, político e historicista. En otras palabras, para el marxismo de Gramsci todos los fenómenos culturales son esencialmente fenómenos históricos, instrumentos en el proceso de la transformación de la realidad.

Las reflexiones teóricas de Gramsci reflejan su profundo interés en el estudio del lenguaje, llegando, incluso, a formular una teoría general del lenguaje con conclusiones muy similares a las que ha llegado la lingüística estructural contemporánea. Una de las influencias más importantes en el enfoque gramsciano ha sido la de su mentor, el conocido neolingüista Matteo Bartoli, quien de acuerdo con Gramsci vio en él "un arcángel enviado a destruir a los neo-gramáticos de una vez por todas" (Gramsci, 1975a, p. 80). Es importante destacar que en el legado textual de Gramsci solamente existen algunas notas sobre los problemas y la historia del lenguaje. Sin embargo, en estas notas hay suficiente material para articular lo que se puede afirmar son los principales componentes de la sociología marxista del lenguaje.

Tomando en cuenta este planteo, en este trabajo me propongo reflexionar sobre los aportes teóricos que realizara Gramsci sobre la teoría del lenguaje y como los mismos constituyen bases fundamentales para el análisis sociológico del lenguaje desde la perspectiva de la teoría creada por Marx.

\section{Gramsci y su enfoque historicista del lenguaje}

La filosofía idealista de Benedetto Croce era, sin duda alguna, la filosofía reinante en Italia. Esta filosofía dominaba todos los campos de la investigación, particularmente la historia, la estética, la literatura, el arte y el lenguaje. Gramsci se propuso la tarea de desarrollar una crítica sistemática de Croce, como Marx lo hiciese con Hegel, y Engels con Dühring. En ese momento, el único elemento común entre Croce y Gramsci era la utilización del enfoque historicista para analizar los fenómenos socioculturales. Esto se evidencia en el tratamiento que 
ambos pensadores le brindan al lenguaje. Así, el manejo conceptual de Gramsci del lenguaje como Weltanschauung, de su historicidad en relación al "espíritu nacional" es un derivado de la filosofía de Croce. Por otra parte, estas ideas eran las dominantes en la filosofía del lenguaje no solo en Italia, sino también en países como Alemania, en donde constituían los basamentos de una corriente de pensamiento filosófico que incluía a pensadores como Herder, Humbolt, Vosier, Trier y Weisgerber, quienes coincidían en asignar un papel creativo al lenguaje en el proceso cognoscitivo, así como en la definición del lenguaje como Weltanschauung. El lenguaje, de acuerdo con este punto de vista, es concebido como un medio para entender la realidad y una concepción del mundo especifica; el lenguaje crea símbolos y a través de ellos la realidad. La tendencia subjetiva (construccionista) de este enfoque es sin duda alguna muy clara (Schaff, 1967, pp. 3-27).

En Italia, en oposición a la escuela neo-gramática cuya mayor preocupación era la formulación de leyes fonéticas, Croce (1992) plantea el problema del lenguaje similar al de la estética. Cada lenguaje es una arte subjetivo de expresión. Como en el arte, la "intuición" es la esencia del lenguaje. Los pensamientos, en su nivel más profundo, se encuentran libres de estructuras lingüísticas específicas. Estas se derivan de una experiencia muy general, abstracta y universal. Como puede comprenderse, la conocida afirmación de Croce es que tanto el lenguaje, como el arte, nunca pueden ser traducidos. Solamente a través de una comprensión intuitiva puede aprehenderse la esencia interna de un lenguaje.

A la concepción subjetivista del lenguaje de Croce, Gramsci ofrece una alternativa de carácter historicista. El lenguaje es un producto social, la expresión de la cultura de una sociedad determinada. La esencia del lenguaje es la historia. Por lo tanto, la mayor preocupación de la lingüística deber ser la historia del lenguaje. Así, dado el carácter histórico de los lenguajes, identificar el lenguaje con el arte es una pérdida de tiempo. La lingüística histórica estudia el lenguaje "no como arte, sino como material del arte, como un producto social, y como la expresión cultural de una población dada" (Gramsci 1975b: 6, VIII, vol. 2, p. 738). Las innovaciones lingüísticas tienen que comprenderse, desde una perspectiva historicista, como innovaciones colectivas que se constituyen en componentes de "la historia de los lenguajes".

La historia de los lenguajes es la historia de las innovaciones lingüísticas, pero estas innovaciones no son individuales (como en el caso del arte). En verdad, son innovaciones de una colectividad social entera que ha renovado su cultura, 
y que ha progresado "históricamente" (Gramsci 1975b: VIII, vol. 2, p. 738).

Como Rosiello (1970) lo hace notar, Gramsci visualiza en el enfoque metodológico neo-lingüístico la confirmación empírica de su lingüística historicista. Dicho enfoque, planteado por Bartoli, combinaba un enfoque metodológico objetivista e historicista. Perseguía dilucidar las causas inmanentes del fenómeno lingüístico, pero siempre desde una perspectiva histórica. Su objetivo, en las palabras de Bartoli, era el establecimiento de una cronología y un estudio de las causas de las innovaciones lingüísticas. La observación de Bartoli en torno a que las innovaciones eran causadas por la influencia cultural e histórica de lenguajes superiores, le indica a Gramsci la seriedad de la "perspectiva historicista" que se encuentra en la neo-lingüística; en tal sentido muestra su superioridad en la relación al enfoque abstracto y subjetivista de Croce y a los planteamientos de los neo-gramáticos (Rosiello, 1970, p. 362).

La neolingüística de Bartoli, a la cual Gramsci se adhiere, fue en efecto influenciada por la tradición lingüística más importante de la Escuela de Ginebra, fundada por Ferdinand de Saussure y cuyo impacto en la lingüística contemporánea es universalmente reconocida. La lingüística de Saussure y la escuela de Durkheim son las fuentes intelectuales indirectas de Gramsci. La concepción del lenguaje de Durkheim como un fenómeno espiritual que trasciende tanto a individuos como a sociedades históricas fue concretizada y colocada en el plano histórico por su portavoz más prominente, Antoine Meillet. Es así como nace una sociología del lenguaje basada en la afirmación que el lenguaje es un proceso social por medio del cual una comunidad establece una institución como un medio colectivo de comunicación. Este enfoque tenia el mérito de establecer una relación íntima entre el lenguaje y la cultura de las sociedades. Los estudios de Malinowski de las "sociedades primitivas" son un ejemplo de que tan difícil es entender los lenguajes "primitivos" separados de su contexto social y cultural (Hertzler 1987).

La lingüística inspirada en el enfoque sociológico-funcionalista de Durkheim no intentó profundizar en el problema de la historicidad el lenguaje. Se limitó a si misma, debido a su orientación positivista, a buscar las leyes lingüísticas del desarrollo en la sociedad y no en la historia. Los cambios socio-estructurales se convertían en la verdadera condición de los cambios lingüísticos. Fue precisamente Saussure que combinó historicismo y objetivismo en un objetivismo histórico, enfoque que se convirtió en una fuente de inspiración para la neo-lingüística de Bartoli. La distinción establecida 
por Saussure entre la lengua y el habla (langage y parole), es aceptada en la mayor parte de los enfoques lingüísticos contemporáneos ya que tiene la virtud de establecer dos tipos de análisis: el sincrónico y el diacrónico. El primero trata con los sistemas lingüísticos como sistemas autónomos e independientes. El segundo, trata con el contexto social e histórico en los que los sistemas lingüísticos se desarrollan. Los dos se complementan mutuamente. $\mathrm{El}$ lenguaje, de esta manera, puede ser analizado en sus aspectos estáticos y dinámicos (Saussure, 1986).

La influencia del método propuesto por Saussure en la construcción gramsciana se evidencia en que ésta también postula un enfoque estático-dinámico para el estudio del lenguaje. La gramática del lenguaje es, según Gramsci, simultáneamente una fotografía de una fase en la evolución histórica del lenguaje y una manifestación del dominio histórico de un sistema lingüístico sobre otros.

El desarrollo de la neo-ingüística italiana fue un proceso marcado por su cercana afiliación con la lingüística de Saussure, que juntamente con la filosofía idealista de Croce, fue instrumental en la liquidación del método de la neo-gramática en la esfera de la lingüística italiana. Sin embargo, de acuerdo con Gramsci, la neo-lingüística fue incapaz de derribar el dominio teórico de Croce. En tal sentido, Gramsci reconoce la superioridad del método de Bartoli en relación al enfoque intuitivo de Croce. La neo-lingüística es un método nuevo, original y progresista del análisis lingüístico. Gramsci, hace notar que:

La innovación de Bartoli es exactamente esta: él construye la lingüística, concebida hasta entonces reduccionistamente como una ciencia natural, en una ciencia histórica cuyas raices se localizan en 'tiempo y espacio' y no en el aparato fonético, en el sentido fisiológico. (Gramsci, $1975 b$ XX, Vol. 1, p. 352)

A pesar del fuerte componente historicista presente en las orientaciones metodológicas de Bartoli, Gramsci está atento a señalar sus debilidades. El problema es que Bartoli no desarrolló, con base en sus hallazgos empíricos, una teoría del lenguaje. Su método mantiene un carácter empírico, con la expresa tarea de investigar solamente las leyes técnicas del desarrollo lingüístico. Y es por esta razón, es que estaba imposibilitado podía en elaborar una teoría general del lenguaje ante la ausencia en su método de una perspectiva filosófica, como por el ejemplo, la del historicismo marxista. Esta perspectiva podría haber producido una lingüística teóricamente independiente, y superior al sistema 
de Croce. En su lugar, capítulo y fue teóricamente relegada por la lingüística de Croce y la de sus seguidores.

La neo-lingüística quedó, de esta forma, petrificada. No desarrolló una teoría del lenguaje. Y lo que es peor, según Gramsci, aceptó el esquema teórico de inspiración croceana, y por tanto mostró su capitulación ante esta perspectiva filosófica. En la prisión, Gramsci planea revivir el método neo-lingüístico y complementarlo con una perspectiva teórica orgánica, sistemática e historicista. Pero antes de comentar las notas de Gramsci sobre el tema, conviene hacer algunas observaciones para caracterizar las particularidades de la lingüística de Gramsci.

Rosiello, uno de los pocos analistas que ha centrado su atención a la lingüística gramsciana, ha evaluado críticamente sus nociones lingüísticas contrastándolas correctamente con la escuela de Saussure y con la lingüística estructural contemporánea. En su evaluación ha establecido los puntos en común entre Gramsci y Saussure; estos son, el énfasis que ambos puntualizan en la importancia de la historia en el análisis lingüístico y sus coincidencias en torno al carácter social del lenguaje. Sin embargo, en Rosiello aparece una imagen incompleta de Gramsci. En su evaluación, Gramsci es descrito como el precursor del estructuralismo contemporáneo, un férreo defensor de una lingüística objetiva, concreta y científica. Lo que es más problemático, Gramsci es presentado como un académico sin otro tipo de compromisos y aspiraciones, por lo tanto nos presenta una imagen muy distinta de la que realmente caracterizó su trayectoria: la de un militante y teórico revolucionario marxista. En Rosiello no se encuentra la formulación de importantes interrogantes en torno a las reflexiones de Gramsci, por ejemplo: ¿Cómo sus análisis del lenguaje están relacionados e integrados a su teoría general del "historicismo absoluto"? ¿Cuál es la naturaleza y el lugar de una "ciencia" del lenguaje en su teoría historicista de la ciencia? ¿Qué tan constante es su adhesión a la neo-lingüística, y su orientación objetivista, con su marxismo humanista? ¿Cómo puede justificarse un estudio desinteresado del lenguaje dado el interés práctico de Gramsci de plantearse que su objetivo principal no consistía en escribir sobre un aspecto de la cultura, sino su intención de modificarla (Gramsci 1975b: 29, XXI, vol. 3, p. 2342)? La asociación de la lingüística de Gramsci con la lingüística estructuralista parece forzada y exagerada. Ciertamente la lingüística tiene su método y un objetivo propio. Gramsci se interesa en desarrollar una teoría y metodología historicista del sistema lingüístico. Su interés es en la "historia del lenguaje" desde una perspectiva de la historia política. La 
investigación empírica de la fonética y de los aspectos morfológicos del lenguaje no es precisamente su principal preocupación, aunque reconoce la importancia de su estudio. Sin embargo, Gramsci afirma en relación a esta problemática que "la ausencia de una concepción crítica e historicista del fenómeno del lenguaje, puede conducir a muchos errores tanto en el campo científico como en el práctico" (1971, p. 451).

\section{El acto lingüístico como un acto político: la esencia de la sociología del lenguaje de Gramsci}

El lenguaje como un sistema de signos no puede analizarse separado del estudio de las ideologías. Los significados contenidos en las palabras son ideológicos, las ideologías son signos. Gramsci, sin embargo, evita el error de identificar mecánicamente el lenguaje con la superestructura. Gramsci está consciente de la necesidad de presentar el lenguaje como entidad "autónoma" tanto de la estructura y como de la superestructura. Así, distingue al interior del lenguaje, una forma y un contenido; es decir, un sistema lingüístico apropiado (organización de signos) de un contenido lingüístico (valores semánticos). El primero se desarrolla y es gobernado por sus propias leyes internas, por lo tanto independiente de la determinación de la estructura. El segundo, es superestructural y como tal debería ser analizado en término de las ideologías y de la praxis política. Gramsci escoge analizar el segundo aspecto del lenguaje, que es de acuerdo con sus convicciones políticas, de primera importancia en el proceso socialista de transformación social.
El contenido del lenguaje indirectamente puede afectar su forma. Gramsci, afirma al respecto: "ninguna situación histórica, no importa que tan radical haya sido el cambio operado, transforma completamente el lenguaje, al menos en su aspecto formal externo. Pero el contenido del lenguaje debe cambiarse." (1971, p. 453)

El aspecto más importante para Gramsci es, entonces, su contenido cultural. Asimismo, está de acuerdo con el principio planteado por Saussure de la arbitrariedad de los signos, indicando el carácter metafórico del lenguaje. Cada lenguaje es metafórico, dice Gramsci, en la medida que contiene "significados" que se han derivado de periodos de civilizaciones pasadas. Fue el concepto de lo metafórico del lenguaje que llevó a Vilfredo Pareto, al igual que a otros pensadores pragmáticos-positivistas, a concebir el lenguaje como fuente de error y las explicaciones lingüísticas como explicaciones sin lógica. Pensadores como Pareto trataron de eliminar 
las metáforas del lenguaje y reemplazarlas con nuevos significados y conceptos científicos. En contraste a esta posición, Gramsci argumenta que los significados metafóricos no pueden ser eliminados del lenguaje.
La transformación de estas metáforas es eminentemente un acto político asociado con la transformación de todas las civilizaciones, por lo tanto,

\begin{abstract}
El lenguaje es transformado [en la medida que se opere] una transformación total de la civilización, a través de la adquisición de la cultura por las nuevas clases y a través de la hegemonía ejercida por uno de los lenguajes nacionales sobre los otros, etc., y lo que hace es precisamente absorber la forma metafórica de las palabras de las civilizaciones y culturas previas. (Gramsci, 1971, pp. 452-453)
\end{abstract}

Si en el lenguaje hay un continuo proceso de formación y transformación de metáforas es porque la "historia" de la cultura se transforma en sí misma. El lenguaje es un acto político y un instrumento de la política. Contribuye a la unidad cultural social soldando una multiplicidad de deseos dispersos en una concepción común del mundo. En este contexto político, Gramsci, argumenta "se asume una gran importancia a la cuestión general del lenguaje, que es la cuestión de lograr colectivamente un 'clima' cultural individual” (1971, p. 439).

Se pueden establecer importantes observaciones metodológicas.
Los hechos lingüísticos no son individuales sino hechos culturales colectivos. Este factor tiene para Gramsci un gran significado político. Si se caracteriza el lenguaje como un fenómeno "colectivo", entonces se tiene que enfatizar en la naturaleza social y dialéctica del lenguaje. El lenguaje es social; es decir, un producto social en el sentido defendido por Durkheim y Saussure. Pero Gramsci agrega que también es dialéctico. En un lenguaje dado, existe una dialéctica entre el lenguaje individual y colectivo, el lenguaje individual se satisface del hecho de ser absorbido por los componentes culturales. Gramsci al respecto dice:

Parece que uno puede decir que el 'lenguaje' es esencialmente un término colectivo que no presupone la existencia de una cosa en tiempo y espacio ... En el límite se podría decir que cada ser parlante tiene un lenguaje personal de sí mismo, que es su propia manera de pensar y sentir. La cultura, en sus dife- 
rentes niveles, unifica a una serie de estratos hasta el punto que mantienen contactos entre ellos, que comprenden sus modos de expresión, etc." (1971, p. 349).

Esto significa que lejos de ser la realización y expresión subjetiva de la cultura, el lenguaje es la expresión de intereses concretos de grupos específicos. Por lo tanto, la diferencia entre el enfoque sociológico-materialista (historicista) de Gramsci y el propuesto por Durkheim es de fundamental importancia teórica y práctica. Mientras que para Durkheim los cambios lingüísticos son un producto de los cambios funcionales en la sociedad, para Gramsci son la conse-

cuencia de la hegemonía de una clase o grupo social sobre la cultura de una sociedad. Gramsci insiste en la estrecha relación entre la estratificación lingüística y la social. Cada clase social tiene su propio lenguaje y una Weltanschauung propia. Las innovaciones lingüísticas tienen que ser explicadas en términos de la influencia molecular de la nueva clase hegemónica sobre las otras. Gramsci, al respecto hace notar:

Cada vez que la cuestión del lenguaje aparece en una forma $u$ otra, significa que una serie de problemas comienzan a emerger: la formación y expansión de la clase dirigente, la necesidad de establecer vínculos más cercanos y firmes entre los grupos dirigentes y las masas nacionales-populares, que es de la reorganización de la hegemonía cultural. (1975b 29 XXI, Vol. 3, 2341)

Los cambios lingüísticos más importantes, continúa Gramsci, son causados por factores externos. Un lenguaje dado refleja los cambios más profundos en el mundo cultural, moral y psicológico.

En el lenguaje no hay partenogénesis; es decir, el fenómeno de un lenguaje produciendo otro lenguaje, sino innovaciones a través de las interferencias de diversos lenguajes. La interferencia y la influencia "molecular" toma lugar al interior de una nación, entre varios estratos (Gramsci 1975b: 6, VII, vol. 2: 739.
Tomando en cuenta lo anteriormente discutido, y desde el contexto general desde el cual Gramsci enfoca el estudio del lenguaje, se pueden establecer un conjunto de proposiciones orgánicas:

La lingüística se preocupa por la historia de los lenguajes;

La historia de los lenguajes es la historia de la semántica, que en sí misma es una parte integral de la historia de la cultura; 
La fuente de "significados en el lenguaje es la historia, y específicamente la praxis política de un grupo determinado;

Los significados son siempre ideológicos, reflejan los intereses de un grupo determinado;

Los significados son críticos en la medida que indican la presencia de elementos derivados de concepciones pasadas o nuevas del mundo;

Existe una dialéctica de significados, que reflejan la dialéctica que existe en la sociedad; $y$

(g) Las verdades lingüísticas son establecidas por la praxis política del grupo dominante.

Para Gramsci, como puede observarse, la lingüística historicista no se preocupa por descubrir las leyes inmanentes, cambios específicos o nuevas direcciones que ocurren en el sistema lingüístico. En su lugar, se enfoca en las "razones prácticas" del por qué una ley, un cierto desarrollo o dirección finalmente prevalece. Desde el punto de vista práctico, de la transformación socialista, por ejemplo, el problema del lenguaje es crucial. Un cambio revolucionario debe ser precedido por una transformación en los significados, un "conformismo lingüístico", en términos gramscianos. En tanto nuevos significados son desarrollados, los viejos se transforman en metáforas. Así, "Normalmente, cuando una nueva concepción reemplaza a una previa, el lenguaje previo continúa siendo usado, pero en términos precisos, metafóricamente. La totalidad de lenguaje es un continuo proceso de metáforas, y la historia de la semántica es un aspecto de la historia de la cultura" (Gramsci 1975a: 450).

El conformismo lingüístico es dictado por la praxis. La tesis de Marcuse de la naturaleza unidimensional del lenguaje, un proceso en el cual los significados y conceptos críticos son eliminados por la praxis tecnológica y reemplazados por conceptos científicos y operacionales, corrobora este punto (Marcuse 1964). La diferencia entre ellos estriba en el hecho que cualquier praxis para Gramsci engendra un conformismo lingüístico.

\section{El carácter histórico y político de la gramática}

Por lo que se ha planteado hasta el momento, el lenguaje en su contenido e historia pertenece a la dimensión superestructural, y, como tal, no escapa a la determinación de la estructura. Sin embargo, las gramáticas como componentes del lenguaje son sistemas con un alto grado de autonomía. Esta afirmación necesita una mayor explicación. En 
una serie de notas sobre Gramatica, una especie de guía introductoria para el estudio del tema, Gramsci plantea varios problemas, algunos parcialmente respondidos, otros apenas enunciados. Su discusión sobre la problemática de la gramática también es conducida desde una perspectiva práctica: como enseñar la gramática históricamente.

La primera cuestión planteada en su polémica con Croce, es acerca de la definición de gramática. Croce escribió un ensayo provocativo titulado "Esta mesa redonda es cuadrada”. Esta expresión, concluye Croce, es equivocada desde el punto de vista de la estética y la lógica, pero correcta desde el punto de vista de los gramáticos. Debe recordarse que la esencia del lenguaje para Croce es la estética. Gramsci critica esta concepción errónea de la gramática (caracterizada como un "sistema técnico") que Croce defiende. Un error gramático denota una ausencia de "disciplina respecto a la historicidad del lenguaje", o simplemente una falta de conocimiento de las razones históricas respecto a las normas gramaticales" (Gramsci 1975b: 29, XXI, vol. 3, 2341). Así, lo que es gramáticamente exacto puede justificarse también desde el punto de vista de la estética y la lógica. La conclusión a que arriba Gramsci es que lo que está en disputa es la definición de gramática. Para Gramsci, "La gramática es 'historia' o un 'documento histórico': es la 'fotografía' de una fase especifica de un lenguaje nacional (colectivo), que se formó históricamente y que continúa su desarrollo, o es el rasgo fundamental de esa fotografía. La pregunta, en el sentido práctico, puede ser: ¿Cuál es el propósito de tal fotografía? Escribir la historia sobre un aspecto de la civilización o modificar un aspecto de la civilización? (Gramsci,1975b, 29, XXI, vol. 3, p. 3241).

Al definir la gramática como un "documento histórico", Gramsci establece una distinción entre dos tipos de gramática: inmanente y normativa. La primera es inherente al lenguaje, en el sentido técnico. Todos hablan de acuerdo a la gramática y a su vez están influenciados por ella. A decir verdad, cada expresión cultural - moral o actividad intelectual, Gramsci nos indica, tiene un lenguaje determinado históricamente. $\mathrm{El}$ segundo, consiste de un sistema de normas derivadas de controles recíprocos, enseñanzas recíprocas, "censuras" recíprocas. "Esta totalidad compleja de acciones y reacciones, para establecer "normas" y estándares de lo que es correcto e incorrecto" (Gramsci 1975b: 29, XXI, vol. 3, p. 2341). La gramática normativa, particularmente cuando es escrita, es instrumental en la creación de una conformidad lingüística nacional o regional.

Rosiello ha observado en la distinción de las gramáticas propuesta por 
Gramsci, una formulación inicial del método estructuralista que asocia el concepto de "gramática inmanente" con la "gramática generativa" y de la cual habla Noam Chomski. El recurso de Gramsci de apoyarse en la forma estructuralista de la lingüística ha sido explicado en términos de su oposición al subjetivismo idealista de Croce (Rosiello, 1970, p. 358). En efecto, Gramsci se opone a Croce no sobre la base de un método lingüístico objetivista, científico; sino se opone a Croce con base a planteamientos historicistas. El historicismo, como se ha indicado, es para Gramsci ¡el método científico par excellence! Los mejores gramáticos son los historiadores del lenguaje, y el mejor tipo de gramática normativa es la gramática histórica. De hecho, la enseñanza de una gramática particular significa la enseñanza de una fase particular de la historia del lenguaje desde cierta posición de clase. Y, el aprendizaje de una gramática significa una interpretación particular del pasado histórico (Gramsci 1975b, 29, XXI, vol. 3, p. 2342).

Desde el punto de vista histórico, Gramsci sigue argumentando, las gramáticas históricas par excellence son las gramáticas comparativas, las únicas capaces de comprender la esencia del lenguaje. La gramática histórica no puede ser sino "comparativa”, una expresión que analizada en toda su extensión indica que tan profunda es la conciencia de que el fenómeno lingüístico, como cualquier otro fenómeno histórico, no puede estar estrechamente definido por fronteras nacionales, sino que la historia es siempre "historia mundial” (Gramsci 1975b: 29, XXI, vol. 3, p. 2342). El contexto político es de este modo central en los análisis gramscianos de las gramáticas. Sin ninguna vacilación, Gramsci afirma que una gramática normativa es un acto político, "la gramática normativa escrita siempre presupone una 'decisión', una orientación cultural, y es por lo tanto un acto de la política nacional-cultural" (Gramsci 1975b: 29, XXI, vol. 3, p. 2342).

La insistencia de Gramsci en la naturaleza histórica y política de la gramática, está relacionada con su intento de desarrollar un enfoque marxista para analizar varios problemas teóricos y prácticos. En primer lugar, Gramsci argumenta contra Croce y Gentile - representantes de la filosofía y del liberalismo político en Italia - que la gramática es más que una "técnica". Es un modo de expresión "históricamente determinado". Y como tal, debería tener un lugar en la teoría general del conocimiento. En segundo lugar, la identificación de gramática con técnica sustentada por Croce tiene el efecto de excluir la gramática de la historia, la filosofía y la teoría, relegando su actividad práctica. Esta posición fue justificada por las políticas educativas impulsadas por Gentile en Italia, las cuales eran opuestas a la enseñanza de cualquier gramática en las escuelas 
y que además proponían un enfoque práctico con base en el laissez-faire: ¡la gramática se aprende hablando! Al respecto de dicha posición, Gramsci la califica como reaccionaria porque fortalece la estratificación social existente. Esta impide el acceso de las masas populares a la cultura alta de los intelectuales y de los estratos sociales privilegiados, la cual tiene la característica de ser transmitida oralmente de generación en generación en una forma parecida a lo que sucede en el caso las castas. Por lo tanto, sostiene Gramsci, es necesaria la enseñanza de una gramática histórica cuyo propósito sea facilitar la consecución de una cultura homogénea con la participación activa de las masas. La enseñanza de la gramática como una "técnica" y como modo de hablar "históricamente determinado" podría, de hecho, capacitar al socialismo en el cumplimiento de una de sus metas fundamentales: elevar el nivel cultural e intelectual de las masas y transformar su Weltanschauungen, su sentido común y su folklore a un nivel superior (Gramsci 1975b: 29, XXI, vol. 3, 2348ff).

Solamente desde esta perspectiva, las notas de Gramsci sobre la lingüística y el estudio de lenguaje pueden ser comprendidas en su dimensión correcta. Los textos de Gramsci sobre esta problemática deben analizarse en relación a los temas centrales de sus escritos de la prisión: la noción de hegemonía y la construcción socialista de un orden intelectual nuevo. Los intereses de Gramsci en la lingüística son, en términos generales opuestos a los de la lingüística estructuralista y positivista contemporánea. A Gramsci le preocupa el contexto político del lenguaje, el lugar del estudio de los lenguajes en una teoría historicista del conocimiento y el papel que juega el lenguaje en la transformación socialista. De nuevo, los puntos básicos de la concepción sociológica que claramente surge en Gramsci son, por una parte, el significado del lenguaje como producto cultural y, por el otro, su reconocimiento que los conflictos sociales intervienen en el establecimiento de las normas lingüísticas. Su concepción sociológica del lenguaje presupone el encuentro de la lingüística histórico-geográfica de su tiempo y la teoría materialista de la historia. En la siguiente sección se mostrará como el análisis de Gramsci de la historia de la lengua italiana viene a confirmar la aplicación de su teoría y metodología. Dicho análisis, es su intento de elaborar una sociología marxista del lenguaje y cuyo objetivo es demostrar la relación práctica e histórica entre el lenguaje y la hegemonía política y cultural de una clase social determinada y la de sus intelectuales orgánicos. 


\section{El conflicto lingüístico como conflicto político: el caso del origen de la lengua italiana}

Leonardo Paggi (1970, p. 76) ha observado que el interés de Gramsci en los estudios lingüísticos lo lleva a examinar el papel y la función histórica de los intelectuales en Italia. Simplemente leyendo las notas de Gramsci sobre el Risorgimiento italiano, se puede observar que tan interrelacionado está el problema del lenguaje con el que corresponde al mundo de los intelectuales. Varias fases de la historia italiana están definidas por la relación específica entre el lenguaje popular y los intelectuales. Cuando los intelectuales escribían o hablaban en un lenguaje que no era entendido por las masas, existió en ese momento una separación entre la cultura alta y la popular.

Gramsci (1975b, 3XX,vol.1,p. 353) observa que una verdadera historia del lenguaje italiano aun no había sido escrita. Uno de sus esfuerzos es precisamente delinear dicha historia, la cual tenía que incluir una discusión del lenguaje como un "elemento de la cultura" y por lo tanto de una "historia general".
En uno de sus primeros ensayos sobre el tema, Gramsci (1975b, p. 30) en su examen de la cuestión del lenguaje en Manzoni, llama la atención del problema de cómo un lenguaje unificado podría ser creado en Italia. Manzoni había afirmado que la unificación lingüística de Italia fue posible solo después de la realización de la unidad política del país y de la creación de un Estado unificado; es decir, solo en el momento cuando los dialectos regionales de Italia han sido eliminados y reemplazados por el Toscano a través de la intermediación del Estado unificado. En contraste a la posición de Manzoni, Gramsci argumenta que la creación de un lenguaje nacional común no es un proceso artificial. La difusión del lenguaje es el resultado de una producción literaria y de las actividades comerciales que se llevan a cabo utilizando ese lenguaje. En ese sentido, Gramsci argumenta lo siguiente:

Entre los siglos XIVy XV. en Toscana había escritores como Dante, Boccacio, Petrarca, Maquiavelo y Guicciardini que difundieron el lenguaje toscano; que, de igual manera, había banqueros, artesanos y fabricantes que llevaban productos toscanos y los nombres de estos productos a través de toda Italia. Mas tarde, cuando la producción de bienes y libros fue restringida, así también fue limitada la productividad del lenguaje. (1975b: 30). 
Como lo observa Paggi (1970:77), desde que era muy joven, Gramsci estaba convencido de la íntima conexión de la historia lingüística y la historia política. "Cada estrato social nuevo que participa en la historia, se organiza a si mismo para una lucha, introduce a la lengua nuevos elementos y nuevos usos y destruye los esquemas fijos que los gramáticos establecieron por razones prácticas y oportunistas" (Gramsci 1975b, p. 33). Esto es el verdadero origen del lenguaje italiano durante el período inicial de la historia italiana, particularmente durante el Renacimiento y el Humanismo, entre los siglos once y quince.

Desde aproximadamente el año 600 hasta alrededor del 1200 de nuestra era, es decir, un período de 600 años, Europa experimentó una completa separación entre las masas y la cultura de los intelectuales. En ese período, estaba el latín literario de las personas privilegiadas y del mundo eclesiástico, y el latín vulgar, del cual se derivaron diversas versiones en toda Europa. La cristalización de estos dos tipos de latín es el resultado histórico del monopolio del conocimiento y de las ideas en general en manos de la casta eclesiástica de intelectuales. La religión que dominaba toda la cultura europea, se transformó paulatinamente abstracta y de esta manera fue entendida, estudiada y predicada en el latín literario de los clérigos y monjes.
En los comienzos del siglo once, varios dialectos se desarrollaron. En Francia, mientras el país se encontraba realizando grandes cambios políticos, económicos, religiosos y culturales, la literatura de la langue d'oc y la langue d'oil comenzó a desarrollarse. De igual modo en Italia, en la medida que el movimiento popular comenzó hacer su presencia en la vida política, aparecieron simultáneamente varios dialectos. Durante el período de las Comunas, ya existían varios dialectos. Entre ellos, solo uno, el volgare illustre prevaleció, debido a la expansión de la hegemonía intelectual de Florencia (Gramsci 1975b: 3, XX, vol. 1, pp. 353-354). Una característica de este dialecto de Toscana, conocido como florentino, el cual se convirtió en la lengua italiana en siglo XII, fue que mientras desarrollaba un vocabulario y una fonética propia, conservaba la sintaxis del latín. Para Gramsci este fenómeno fue el resultado de la preeminencia de los intelectuales tradicionales, los eclesiásticos, que no eran intelectuales nacionales sino cosmopolitas que se dirigían a una audiencia europea cristiana. Bosquejemos, a continuación, los sucesivos desarrollos de la lengua italiana, de acuerdo con las propias palabras de Gramsci (1975b: 3, XX, vol.1, 353-354).

Con la caída de las Comunas, con el advenimiento de los Principados y la creación de un gobierno de castas separado de la gente, este dialecto se 
cristalizó. De nuevo, el italiano es un lenguaje escrito pero no hablado, un lenguaje de los literatos y no de la nación. Hay dos lenguajes culturales en Italia, el latín y el italiano. Este último prevalece y se convierte en el dominante de una manera completa en el siglo diecinueve con la separación de los intelectuales legos de los eclesiásticos.

¿Cómo podemos explicar estos desarrollos lingüísticos? Gramsci hace dos importantes observaciones. El nacimiento de varios dialectos marcan el rompimiento histórico con la cultura medieval y la afirmación de un dialecto, el florentino, sobre el resto de dialectos ha sido el resultado de la concentración de grupos intelectuales. Gramsci rechaza fuertemente la interpretación de los desarrollos lingüísticos elaborada por el historiador Vittorio Rossi, así como la de su interpretación del período del Renacimiento. De acuerdo con Rossi, el movimiento inicial del Renacimiento es la culminación, y la manifestación espontánea de las energías creativas surgidas de lo más profundo de la conciencia del hombre (sic), deseoso de sentir y vivir "la antigüedad". Gramsci por el contrario argumenta que el surgimiento de nuevos dialectos representa una dramática ruptura con la cultura medieval y con las instituciones y valores feudales. El conflicto entre el lenguaje latín y los nuevos dialectos fue la manifestación de un conflicto más profundo entre dos concepciones del mundo. Por un lado, existía un mundo intelectual aristocrático-feudal, ligado a la antigüedad romana y que se expresaba en latín. Por el otro, existía una nueva y progresista civilización burguesa-popular que se expresaba en nuevas lenguas para afirmarse con nuevas exigencias y valores. El carácter espontáneo del Renacimiento Italiano del siglo XI fue una reacción burguesa contra el régimen feudal que afectaba todos los aspectos de la sociedad, particularmente la vida económica, política y cultural. La nueva clase burguesa desarrolló la agricultura, la industria y el comercio, proceso que culminó dando lugar al fenómeno de las comunas. El Renacimiento espontáneo fue seguido de un Renacimiento humanista y cultural que se extendió hasta el siglo XV. Este hecho histórico representó un renacer del latín como lengua de los intelectuales opuesta a los nuevos dialectos. La burguesía progresista, después de la caída de las Comunas, fue contenida y finalmente suprimida por las fuerzas regresivo-reaccionarias, por una aristocracia separada de las masas.

La nueva cultura italiana, que surge en el siglo XI, no era "nacional" sino "regional" y "comunal". La unificación lingüística de Italia se llevó a cabo en el siglo XV. La burguesía reaccionó contra una cultura europea, católica, abstracta universalista y expresó su interés práctico 
a través de nuevos dialectos. Sin embargo, Gramsci continúa, la nueva burguesía emergente no podía crear un "lenguaje nacional" precisamente porque sus intelectuales fueron absorbidos por los intelectuales tradicionales y reaccionarios. El Humanismo, con su culto a la antigüedad clásica, es para Gramsci un período reaccionario. Así, queda demostrado que tan fuertes y poderosos fueron los estratos intelectuales vinculados al mundo feudalaristocrático (Gramsci 1975b, 5, IX, vol. 1, p. 640).

Pero, ¿cómo explicar la cristalización del volgare illustre? En palabras de Gramsci, ¿Por qué el dialecto florentino fue capaz de transformarse en hegemónico en la literatura y la cultura mientras que la nueva burguesía-popular no era capaz de ejercer una hegemonía sociopolítica? El mismo Gramsci responde a la interrogante bosquejando un análisis breve del papel de los intelectuales durante el Renacimiento y el periodo humanista.

El periodo de las Comunas, de las libertades comunales, señala Gramsci, fue caracterizado por un ascenso político de las masas populares. Los nuevos intelectuales vinculados a la burguesía, nacidos de las clases populares (burguesas), prosperaron y se desarrollaron hasta tal punto que fueron capaces de crear una nueva literatura italiana, escrita y hablada en los nuevos dialectos. En el período postcomunal, estos intelectuales fueron absorbidos por la casta tradicional de la aristocracia. Para dejar este punto claro, los intelectuales continuaron saliendo de las masas populares, pero fueron individualmente seleccionados y asimilados por la casta tradicional de intelectuales, los eclesiásticos. Los logros muy limitados de la burguesía comunal y de las actividades literarias populares pueden explicarse, Gramsci continúa, solamente si se considera el papel ambivalente de los intelectuales. Petrarca, por ejemplo, fue un poeta de la burguesía y escribió en el dialecto florentino. Pero también escribió sobre temas políticos utilizando el latín. Así, Petrarca fue un intelectual de la reacción antiburguesa en el período de los Principados.

El periodo Renacentista en el cual surge el nuevo dialecto, es para Gramsci un período progresista en la historia de Italia. En este momento, las nuevas fuerzas populares hacen su aparición en la historia pero no pudieron consolidarse políticamente, pues sus intelectuales fueron incapaces de mantener su autonomía política vis-a-vis los intelectuales tradicionales, el estrato social de los clérigos, íntimamente ligados a viejo régimen aristocrático-feudal. El Humanismo es un período reaccionario, es el período de restauración del viejo mundo feudal y de la pérdida de la unidad cultural. El movimiento humanista prevaleció 
tanto política como ideológicamente. Políticamente, conteniendo y reprimiendo a las clases burguesas revolucionarias; intelectualmente, a través de la asimilación de los principios ideológicos de la burguesía. El retorno al lenguaje "latín" y al culto de los clásicos fue un movimiento político e ideológico que condujo a la contra-reforma. El triunfo del culto de los romanitas tiene que explicarse en términos de la reafirmación del poder político de los Papas, y del restablecimiento del Sacro Imperio Romano (Gramsci 1975, IX, vol. 1 p., 645).

Es esta historia que Gramsci tiene presente cuando escribe que el lenguaje es un fenómeno político y que una gramática histórica aun no había sido escrita. La lengua italiana es el dialecto de una clase; la de un grupo social que se hace valer a sí mismo en reacción a los intereses feudales, aristocráticos y universales $y$ en la defensa de los recientemente surgidos intereses popularesburgueses.
En conclusión, en los textos de Gramsci, no podemos encontrar un análisis sistemático y orgánico del lenguaje para afirmar que en ellos existe, con todas sus formalidades, una sociología marxista del lenguaje. Sin embargo, de todas sus notas fragmentarias sobre el lenguaje, se puede concluir que un claro esquema analítico marxista, ha sido desarrollado por el revolucionario italiano. Cada gramática refleja la historia de una clase social en ascenso hacia el logro de una hegemonía política y cultural. Gramsci busca una evidencia empírica e histórica para confirmar esta idea. La historia del origen de la lengua italiana le proporciona la mejor ilustración de su tesis. Por consiguiente, los conflictos lingüísticos son expresión de una lucha entre clases y grupos sociales en su búsqueda por construir una hegemonía política y cultural. Este es el objetivo de la sociología gramsciana del lenguaje.

\section{Referencias bibliográficas:}

- Angliani, B. (1967). La critica literaria in Gramsci. Critica Marxista (3), pp. 208-209.

- Croce, B. (1992). The Aesthetic as the Science of Expression and of Linguistics in General, Part 1. Cambridge University Press.

- Gramsci, A. (1971). Selections from Prison Notebooks. International Publishers.

- __ (1975a). Letters from Prison. Harper. 

. (1975b) .Quaderni del Carcere. Edizione critica dell'Istituto Gramsci. Giulio Einaudi Editore.

- __ (1975c). "Socialism and culture”, en Cavalcanti, P. y Piccone, P. (Eds.), History, Philosophy and Culture in the Young Gramsci. Telos.

- Durkheim, E. (1972). Selected Writings. Cambridge University Press.

- Hertzler, J. (1987). A Sociology of Language. Random House.

- Marcuse, H. (1964). One Dimensional Man: Studies in the Ideology of Advanced Industrial Society. Beacon Press.

- Paggi, L. (1970). Gramsci e il moderno principe. Editori Riuniti.

- Petronio, L. (1958) “Gramsci e la critica letteraria”, en Studi Gramsciani. Atti del convegno tenuto a Roma nel giorni 11-13 gennaio 1958. Istituto Gramsci y Editore Riuniti , pp. 223-241.

- Rosiello, L. (1970) “Problemi linguistici negli scriti di Gramsci”, en Gramsci e la Cultura Contemporanea. Atti del convegno internazionale di studi gramsciani tenuto a Cagliari il 23-27 aprile 1967. Istituto Antonio Gramsci y Editore Riuniti, pp. 223-234.

- Saussure, F. (1986). Course in General Linguistics. Open Court Publishing Co.

- Schaff, A. (1973). Language and Cognition. McGraw-Hill. 